\title{
Influence of group member familiarity on online collaborative learning
}

\author{
Jeroen Janssen, Gijsbert Erkens, Paul Kirschner, and Gellof Kanselaar, Research Centre Learning Interaction, \\ Utrecht University, The Netherlands. \\ J.J.H.M.Janssen@fss.uu.nl, G.Erkens@fss.uu.nl, P.A.Kirschner@fss.uu.nl, G.Kanselaar@fss.uu.nl
}

\begin{abstract}
This study investigated the effects of group member familiarity during computersupported collaborative learning. Familiarity may have an impact on online collaboration, because it may help group members to progress more quickly through the stages of group development, and may lead to higher group cohesion. It was therefore hypothesized that increased familiarity would lead to (a) more critical and exploratory group norms, (b) more positive perceptions of online communication and collaboration, (c) more efficient and positive collaboration, and (d) better group performance. To investigate these hypotheses, 105 secondary education students collaborated in groups of three. The results of this study indicate that familiarity led to more critical and exploratory group norm perceptions, and more positive perceptions of online communication and collaboration. Furthermore, in familiar groups students needed to devote less time regulating their task-related activities. On the other hand, no effect of familiarity on group performance was found.
\end{abstract}

\section{Introduction}

Over the past 20 years, research on computer-supported collaborative learning (CSCL) has helped support the claim that collaborative activity among students can effectively be supported with computer technology. The accumulated knowledge concerning effective CSCL has also led to detailed design guidelines for CSCL (e.g., Kirschner, Martens, \& Strijbos, 2004). In spite of these design guidelines, researchers still experience problems when students collaborate using computer technology (e.g., conflicts, communication difficulties, shallow discussions). Although these problems may be caused by poor implementation of the design guidelines mentioned, it may also be the case that research has focused too little on potential moderators that can influence the effectiveness of CSCL (Hollingshead \& McGrath, 1995) such as time spent on group work (e.g., one session versus prolonged group work), task type (e.g., open versus closed tasks), group size (e.g., small versus large groups), and group or student characteristics (e.g., estrangement versus familiarity of group members). For example, how well students know each other prior to their collaboration may have an impact on several aspects of their collaboration (Kiesler \& Sproull, 1992). Ignoring such moderators may lead to inconsistent and contrasting results, making it very risky to draw generalizations.

The aim of this contribution is to examine the effect of one potential moderator, namely group member familiarity. Kiesler and Sproull (1992) identified group member familiarity as an important factor to consider when designing CSCL. The effects of familiarity on group interaction and performance are related to aspects of Tuckman's (1965) stages of group formation: forming, storming, norming, and performing. It has been hypothesized that when group members know each other well, they will spend less time forming a coherent group, and will establish group norms more easily, and thus, reach the performing stage more quickly. This is thought to have beneficial effects for, among others, satisfaction with online collaboration and group performance (Adams, Roch, \& Ayman, 2005).

Although only a small number of studies has investigated the impact of group member familiarity on CSCL (e.g., Adams et al., 2005; Mennecke, Hoffer, \& Valacich, 1995; Smolensky, Carmody, \& Halcomb, 1990), researchers have identified possible positive and negative consequences of increased familiarity among group members. For example, Adams et al. (2005) found that when group members knew each other better, their satisfaction with the group process increased, though their decision accuracy decreased. Similarly, Smolensky et al. (1990) found that familiarity had a negative impact on students' interactive behavior, which, in turn led to decreased group performance. In contrast, Mukahi and Corbitt (2004) found no relationship between familiarity and students' collaborative activities. 
An explanation for the mixed results may be the different operationalizations of familiarity (Adams et al., 2005). Adams et al., for example, following Gruenfeld, Mannix, Williams, and Neale (1996), asked students to rate familiarity with group members on a 4-point scale. Smolensky et al. (1990), on the other hand, did not measure familiarity directly but asked half of their participants to bring two friends to their experiment, so as to create familiar and unfamiliar groups, thus equating familiarity with friendship. In our opinion, students can be familiar with each other without being friends. In this study, familiarity was operationalized by asking students, before the start of their collaboration, to indicate how well they knew the other group members. This way, the collaboration itself does not affect students' judgments of familiarity. On the other hand, asking students to rate familiarity before the collaboration may draw attention to whether they worked with friends or strangers, which may also influence students' collaborative behavior.

Our study differed from previous studies on familiarity on several aspects. In contrast to other studies, students in our sample came from existing secondary education classes, thus most group members knew their teammates to a certain extent, although variations obviously existed. In other studies, students were recruited from a pool of student volunteers (Adams et al., 2005). Additionally, the study presented here was carried out in an authentic educational context, in which students collaborated online for a longer period of time. In contrast, in other studies the effects of familiarity were often examined in a single online session, while students worked on group tasks with little or no relationship to the curriculum (e.g., Mennecke et al., 1995; Orengo Castellá, Zornoza Abad, Prieto Alonso, \& Peiró Silla, 2000). Furthermore, most studies that examined the role of familiarity during online collaboration focused on either students' perceptions (e.g., their satisfaction with the collaborative process) or on students' interactive behavior (e.g., use of negative speech). This study will focus on perceptions as well as behavior.

Thus, in order to extend the research findings concerning familiarity, this paper focuses on the effects of familiarity on (a) perceived group norms, (b) perceptions of online collaboration and communication, (c) students' collaborative activities, and (d) group performance. The remainder of this introduction focuses on describing the possible effect familiarity may have on these four variables.

\section{Group norms}

As groups include group members who are more familiar with one another, students may be more comfortable expressing disagreement (Gruenfeld et al., 1996). As such, familiarity may help group members to adopt critical or exploratory group norms instead of consensus norms (Postmes, Spears, \& Cihangir, 2001). This is important because critical or exploratory group discussions have been shown to lead to more effective group work (Wegerif, Mercer, \& Dawes, 1999). During critical group discussion, students do not hesitate to question each others' opinions, that is to disagree with one another (Postmes et al.). Exploratory group discussions are similar to critical group discussions in the sense that students accept criticism from each other and discuss alternatives. In addition, these kinds of discussions should be held in a constructive manner. In other words, conflicts and disagreements are welcome, but group members should try to resolve them. Furthermore, during exploratory discussions group members share relevant information and encourage each other to participate (Wegerif et al.). It is expected that familiar group members will be more likely to develop group norms which value critical or exploratory online discussions because they do not feel the social pressure to agree with other group members (Adams et al., 2005). Unfamiliar group members may be more prone to adapt to such pressure. These critical or exploratory versus consensual group norms will be developed in the norming stage of group formation (Tuckman, 1965). Thus, the following hypothesis may be formulated:

\section{H1 Group member familiarity will contribute to more critical and exploratory group norms.}

\section{Perceptions of online communication and collaboration}

In familiar groups, group cohesion will likely be higher because group members feel more comfortable with the other members (Adams et al., 2005; Mennecke et al., 1995). Furthermore, when group members know each other better, they may be able to communicate and collaborate efficiently (Adams et al.). This will lead familiar group members to perceive their online communication and collaboration within their group as being more positive. Students may also perceive their communication and collaboration more positively in familiar groups because psychological safety is higher in these groups (Van den Bossche, Gijselaers, Segers, \& Kirschner, 2006). Indeed, studies by Mennecke et al. and Adams et al. found more positive perceptions of communication and collaboration in familiar groups. Therefore, a second hypothesis will be investigated: 
H2 Group member familiarity will lead to positive perceptions regarding the collaborative process.

\section{Collaborative activities}

As familiarity between group members increases, communication and coordination of collaboration may take less effort. For example, the transfer of information relevant to executing the task may be more efficient, and misunderstandings may be less likely to occur. This can be explained by the higher amount of knowledge available to familiar group members of other member's skills, expertise and communication styles (Adams et al., 2005). Familiar group members may share a social history, making it easier to understand each other and know each other's strengths and weaknesses. Similarly, familiarity may decrease the need for extensive regulation and coordination of task and group processes. Consequently, a third hypothesis will also be investigated.

H3 Group member familiarity will influence collaborative activities. More specifically, transfer of information, regulation of task and group processes, and misunderstandings will decrease, while indications of understanding will increase.

\section{Group performance}

In light of the above, it is likely that the increased knowledge of group members' skills and modes of interaction will help familiar groups outperform groups of strangers. For example, familiar groups will experience less process loss (e.g., misunderstandings) and be more inclined to pool information resources to effectively carry out the group task (Gruenfeld et al., 1996). Furthermore, if H1 is true, then familiar groups may hold more critical and exploratory group norms, which help them engage in argumentative interactions. Finally, collaboration may be more efficient because familiar groups do not need to devote as much time to regulating and coordinating task and group processes. Therefore, this study will address a fourth and final hypothesis:

H4 Group member familiarity will increase group performance.

\section{Method and Instrumentation}

\section{Participants}

The participants were students who came from five different history classes from two secondary schools working in small groups. The total sample consisted of 105 eleventh-grade students (47 male, 56 female). The mean age of the students was 16.17 years $(S D=.57, \operatorname{Min}=15, \operatorname{Max}=18)$. The participants were randomly assigned to 35 different 3-person groups. It is important to note that students were assigned to groups within their own class and did not collaborate with students from other classes or schools.

\section{Tasks and materials}

\section{CSCL-environment: Virtual Collaborative Research Institute}

Group members collaborated in a CSCL-environment called Virtual Collaborative Research Institute (VCRI, see Figure 1), a groupware program designed to support collaborative learning on inquiry tasks and research projects. VCRI has been used in several research projects (Janssen, Erkens, \& Kanselaar, 2007). Students used VCRI to communicate with each other, access information sources, and co-author texts and essays. Teachers also used the program to monitor online discussions and student progress. While working with VCRI, students share several tools, such as a Sources-tool which contains information sources that students can use to gather important information, a Chat-tool for synchronous communication with group members, a Cowriter for shared word processing, which students can use to simultaneously compose their texts or answers, and a Diagrammer for making external representations of ideas or arguments. Other tools not shown in Figure 1 include a Planner and a Logbook.

\section{Inquiry group task}

Participants worked on a historical inquiry task on "The first four centuries of Christianity". The task consisted of three parts. First, the groups had to answer four different questions using 12 different historical sources. To complete the second part of the task, the groups had to study 40 different information sources and categorize them into five different categories. Students had to decide together on which categories they would use. This categorization had to be visualized in a diagram, using the VCRI-diagrammer. Finally, they had to co-write an essay 
of at least 1200 words. The essay had to explain why and how Christianity developed from a small 'cult' into the main religion of the Roman Empire. In sum, the group task was an open-ended task, without a standard procedure and with no single correct answer.

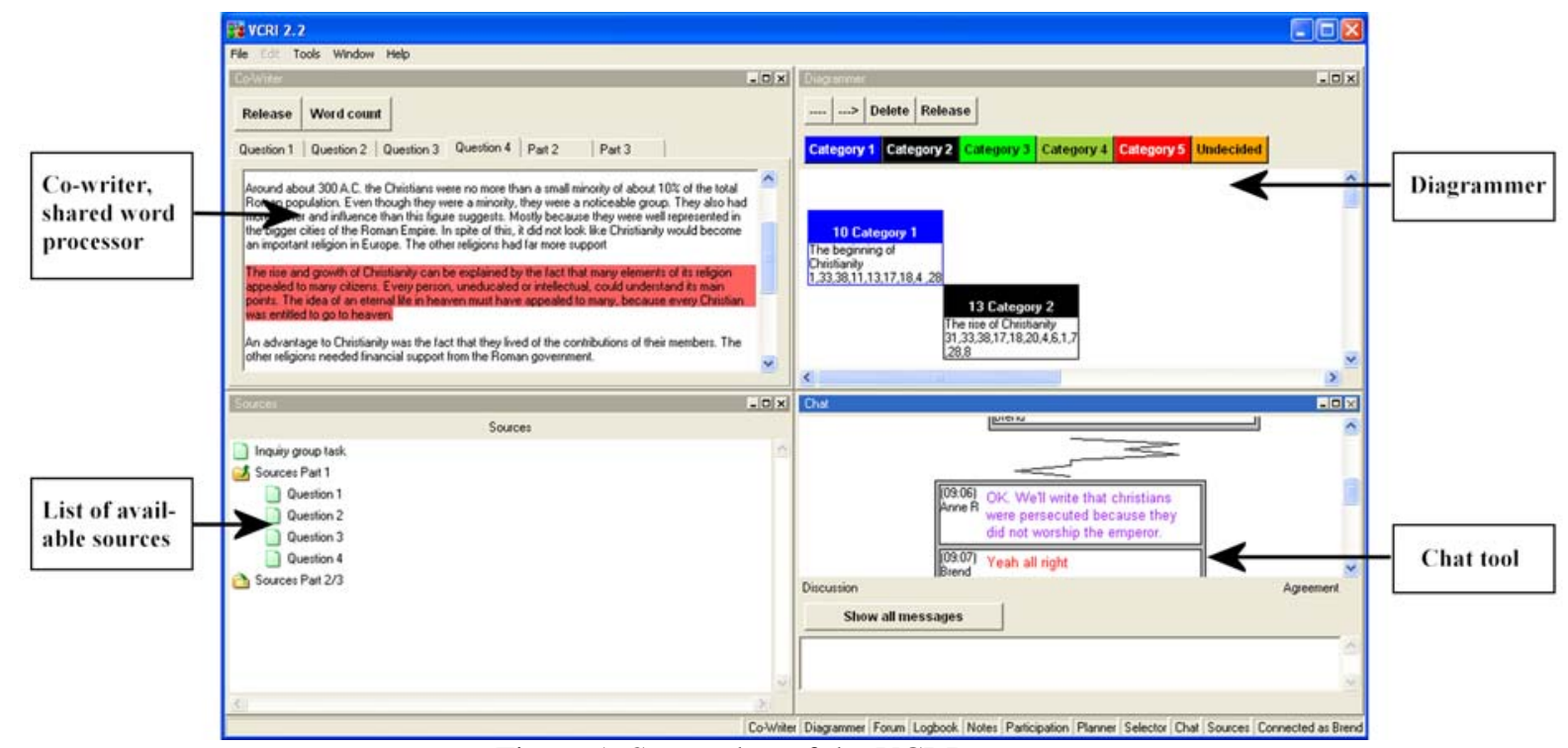

Figure 1. Screenshot of the VCRI-program.

\section{Procedure}

In total, students devoted eight, 50-minute lessons to the inquiry task. During the lessons, each student worked on a separate computer in a computer lab. Before the first computer lessons, students received information about the task and the group composition. Furthermore, students completed a pretest questionnaire, requesting personal information (e.g., age, gender) and which asked them about how familiar they were with the other group members (see Independent measure section below). During the computer lessons, teachers were standby to answer task-related questions. In addition, students were allowed to work on the inquiry group-task during their free periods in the schools' media centers. After the last lesson, a posttest questionnaire was administered containing items on group norm perception and perception of online collaboration. Students expressed their opinions using a 5-point scale ranging from 1 (= completely disagree) to 5 (= completely agree).

\section{Independent measure: Familiarity}

Students' perceived familiarity with the other group members served as the independent measure for this study. Based on work by Gruenfeld et al. (1996) and Adams et al. (2005), familiarity was measured by asking each student, before the start of the collaboration, to rate his or her two other group members on a 4-point scale, ranging from 1 (= do not him/her know at all) to 4 (= know him/her very well). This question was preceded by four specific 'yes/no' questions designed to remind students of situations which they had previously encountered with the other group members in order to help them better judge group member familiarity. Subsequently, the two ratings for each group member were summed to create an overall familiarity score, which reflected the level of familiarity of the individual student with his or her group members. Thus, the familiarity score could range from 2 to 8.

Sometimes however, group members disagreed as to how well they thought they knew each other. These disagreements may undermine the reliability of the familiarity measure. Therefore, group members' familiarity ratings of each other were compared. An agreement percentage of $64 \%$ was found (Cohen's $\kappa=.50$ ). However, this interrater reliability is a strict measure of reliability, because differences of one point (e.g., one student rated his familiarity with the other with a three, while the other gave a four) are considered disagreements. Therefore, we computed a correlation between students' familiarity ratings of each other. This correlation between familiarity ratings of group members was highly significant $(r=.79, p<.01)$, which shows that there was consistency between group members' familiarity ratings. This also points to an adequate reliability of the familiarity measure. Additionally, the validity of the familiarity measure was examined by correlating the sum of the four 'yes/no' 
questions (higher scores reflect higher familiarity) with the familiarity measure. A significant correlation was found $(r=.70, p<.01)$. This provides evidence for the validity of the overall familiarity score.

\section{Dependent measures Questionnaire data}

To investigate hypotheses 1 and 2, data from the posttest questionnaire were used. The questionnaire contained three scales for group norm perceptions, and three scales for perception of online collaboration, which are summarized in Table 1. All of the scales had adequate reliability coefficients. Thus, for all scales students' ratings on the individual items were averaged to create a mean score.

Table 1: Summary of the scales in the posttest questionnaire.

\begin{tabular}{|c|c|c|c|c|}
\hline $\mathrm{H}_{\mathrm{n}}$ & Scale(s) & Description & Items & $\alpha$ \\
\hline \multirow[t]{3}{*}{1} & Critical group norm perception & $\begin{array}{l}\text { Based on Postmes et al. (2001): Were students } \\
\text { critical of each other? }\end{array}$ & 3 & .85 \\
\hline & $\begin{array}{l}\text { Consensual group norm } \\
\text { perception }\end{array}$ & $\begin{array}{l}\text { Based on Postmes et al.: Was there mostly } \\
\text { consensus in the group? }\end{array}$ & 3 & .60 \\
\hline & $\begin{array}{l}\text { Exploratory group norm } \\
\text { perception }\end{array}$ & $\begin{array}{l}\text { Based on Wegerif et al. (1999): Were discussions } \\
\text { constructively critical? }\end{array}$ & 7 & .73 \\
\hline \multirow[t]{3}{*}{2} & Positive group behavior & $\begin{array}{l}\text { Behaviors such as equal participation, helping, etc. } \\
\text { Higher scores reflect more positive group behavior. }\end{array}$ & 7 & .83 \\
\hline & Negative group behavior & $\begin{array}{l}\text { Behaviors such as conflicts and free riding behavior. } \\
\text { Higher scores reflect more negative group behavior. }\end{array}$ & 5 & .66 \\
\hline & $\begin{array}{l}\text { Perceived effectiveness of group } \\
\text { task strategies }\end{array}$ & $\begin{array}{l}\text { Choices made and strategies chosen to complete } \\
\text { group task. }\end{array}$ & 8 & .81 \\
\hline
\end{tabular}

\section{Collaborative activities}

To examine the influence of familiarity on collaborative activities, a coding scheme (Janssen et al., 2007) was used to gain insight into the task- and group-related processes carried out during students' online collaboration. The scheme contained four dimensions: task-related activities, regulation of task-related, social activities, and regulation of social activities. Each dimension contained two or more coding categories. Furthermore, the scheme included several additional categories (e.g., technical aspects) that did not belong to any of the four dimensions. In total, the scheme consisted of 19 categories. Table 2 shows all coding scheme codes. Two researchers determined the interrater reliability of the coding procedure, by independently coding 796 collaborative activities. The overall Cohen's $\kappa$ was .94. The category Kappas (Cicchetti, Lee, Fontana, \& Dowds, 1978) are also given in Table 2.

\section{Group performance scores}

To measure the effect of familiarity on group performance, an assessment form was developed for each part of the inquiry task. The assessment form for the first part addressed (1) conceptual content and quality of argumentation of the answers, and (2) quality of the presentation of the answers. Conceptual content and quality of argumentation were assessed using one item on a 4-point scale. Quality of the presentation was assessed using five items (e.g., correctness of the language used, structure of the written answer) that were rated on a 3-point scale. The assessment form for the second part of the task part consisted of three items which assessed the quality and completeness of the constructed diagram and the quality of the explanation. These items were also rated on a 3point scale. For the last part of the inquiry task, group members needed to collectively write an essay. Comparable to part one, conceptual content and quality of argumentation were assessed using three items rated on a 3-point scale. Quality of the presentation of the essay was assessed using five items on a 3-point scale. This was done in a similar fashion as for part one of the inquiry task. To check the objectivity of the assessment procedure, two researchers scored seven inquiry tasks. The results of reliability analysis were satisfactory, as Cohen’s $\kappa$ ranged from .73 to .90 . 
Table 2: Collaborative activities (abbreviation) and category Kappas $\left(\kappa_{\underline{c}}\right)$.

\begin{tabular}{|c|c|c|c|c|}
\hline & \multicolumn{2}{|l|}{ Task-related activities } & \multicolumn{2}{|l|}{ Social activities } \\
\hline & Codes & $\kappa_{c}$ & Codes & $\kappa_{c}$ \\
\hline $\begin{array}{l}\text { Perfor- } \\
\text { mance }\end{array}$ & $\begin{array}{l}\text { - Info exchange (TaskExch) } \\
\text { - Asking questions (TaskQues) }\end{array}$ & $\begin{array}{l}.93 \\
.86\end{array}$ & $\begin{array}{ll}\text { - } & \text { Greetings }(\text { SociGree }) \\
\text { - } & \text { Social support }(\text { SociSupp }) \\
\text { - } & \text { Social resistance }(\text { SociResi) } \\
\text { - } & \text { Mutual understanding }(\text { SociUnd }+) \\
\text { - } & \text { Loss of mutual understanding } \\
& (\text { SociUnd-) }\end{array}$ & $\begin{array}{l}.97 \\
.90 \\
.91 \\
.94 \\
.87\end{array}$ \\
\hline $\begin{array}{l}\text { Coordi- } \\
\text { nation } \\
\text { / regulation }\end{array}$ & $\begin{array}{l}\text { - Planning (MTaskPlan) } \\
\text { - Monitoring (MTaskMoni) } \\
\text { - Positive evaluations (MTaskEvl+) } \\
\text { - Negative evaluations (MTaskEvl-) }\end{array}$ & $\begin{array}{l}.94 \\
.93 \\
.78 \\
.91\end{array}$ & $\begin{array}{ll}- & \text { Planning (MSociPlan) } \\
\text { - } & \text { Monitoring (MSociMoni) } \\
\text { - } & \text { Positive evaluations (MSociEvl+) } \\
\text { - } & \text { Negative evaluations (MSociEvl-) } \\
\end{array}$ & $\begin{array}{r}.88 \\
.96 \\
1.00 \\
-\end{array}$ \\
\hline Other & $\begin{array}{l}\text { - Neutral technical (TechNeut) } \\
\text { - Negative technical (TechNega) } \\
\text { - } \quad \text { Positive technical (TechPosi) }\end{array}$ & $\begin{array}{r}1.00 \\
.89 \\
1.00\end{array}$ & - $\quad$ Other / nonsense (Other) & 1.00 \\
\hline
\end{tabular}

\section{Results}

\section{Group norm perception}

Table 3 shows the means and standard deviations of familiarity and the three measures of group norm perception, and their intercorrelations. As can be seen from this Table, students reported an average familiarity $(M=4.24, S D=1.48)$ with their group members. Furthermore, familiarity correlated significantly with several dependent variables.

Table 3: Means, standard deviations, and intercorrelations for familiarity, group norms, and perceptions of online behavior $(N=88)$.

\begin{tabular}{|c|c|c|c|c|c|c|c|c|c|}
\hline & $M$ & $S D$ & 1 & 2 & 3 & 4 & 5 & 6 & 7 \\
\hline 1. Familiarity $^{\mathrm{a}}$ & 4.24 & 1.48 & -- & .13 & .14 & $.27^{*}$ & $.28^{* *}$ & $-.28^{*}$ & $.26^{*}$ \\
\hline \multicolumn{10}{|c|}{ Group norm perceptions } \\
\hline 2. Critical $^{\mathrm{C}}$ & 3.25 & 0.75 & & -- & $.34^{* *}$ & $.41^{* *}$ & $.30^{* *}$ & -.01 & $.30^{* *}$ \\
\hline 3. Consensual ${ }^{\mathrm{C}}$ & 3.50 & 0.62 & & & - & $.68^{* *}$ & $.68^{* *}$ & $-.34^{* *}$ & $.55^{* *}$ \\
\hline 4. Exploratory ${ }^{c}$ & 3.71 & 0.53 & & & & -- & $.76^{* *}$ & $-.42^{* *}$ & $.65^{* *}$ \\
\hline
\end{tabular}

Perception of online

behavior

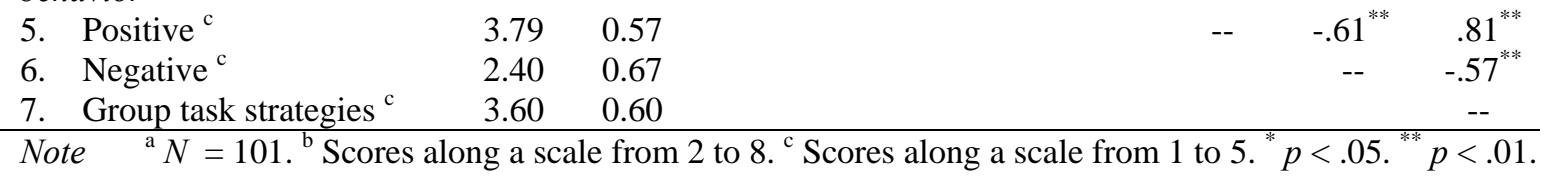

Because the data were nested (i.e., students worked in groups), and because there was interdependence between group members' scores (i.e., group members could influence each other) multilevel analysis was used to examine the effects of familiarity (Kenny, Kashy, \& Cook, 2006). The results of these analyses are summarized in Table 4 . The $\beta$ - and $t$-values show that familiarity had a significant positive effect on students' perceived critical and exploratory group norms. Students who knew their other group members well, reported higher perceived critical and exploratory group norms. No effect was found for familiarity on consensual group norm perceptions. 
Table 4: Multilevel analyses of the effect of familiarity on group norm perceptions and perceptions of online behavior.

\begin{tabular}{lcccc}
\hline & $\beta$ & SE $\beta$ & $t$ & $\chi^{2}$ \\
\hline Group norm perceptions & & & & \\
1. Critical & 0.094 & 0.061 & $1.54^{*}$ & $4.82^{* *}$ \\
2. Consensual & 0.061 & 0.048 & 1.27 & $5.82^{* *}$ \\
3. Exploratory & 0.100 & 0.039 & $2.49^{* *}$ & $10.60^{* *}$ \\
& & & & \\
Perception of online behavior & & & & \\
4. Positive & 0.103 & 0.044 & $2.35^{* *}$ & $10.09^{* *}$ \\
5. Negative & -0.125 & 0.048 & $-2.60^{* *}$ & $13.09^{* *}$ \\
6. Effectiveness group task strategies & 0.105 & 0.046 & $2.26^{* *}$ & $6.45^{* *}$ \\
\hline
\end{tabular}
${ }^{*} p<.05 .{ }^{* *} p<.01$.

Fragment 1: Low familiarity group (line number, student ID, chat message).

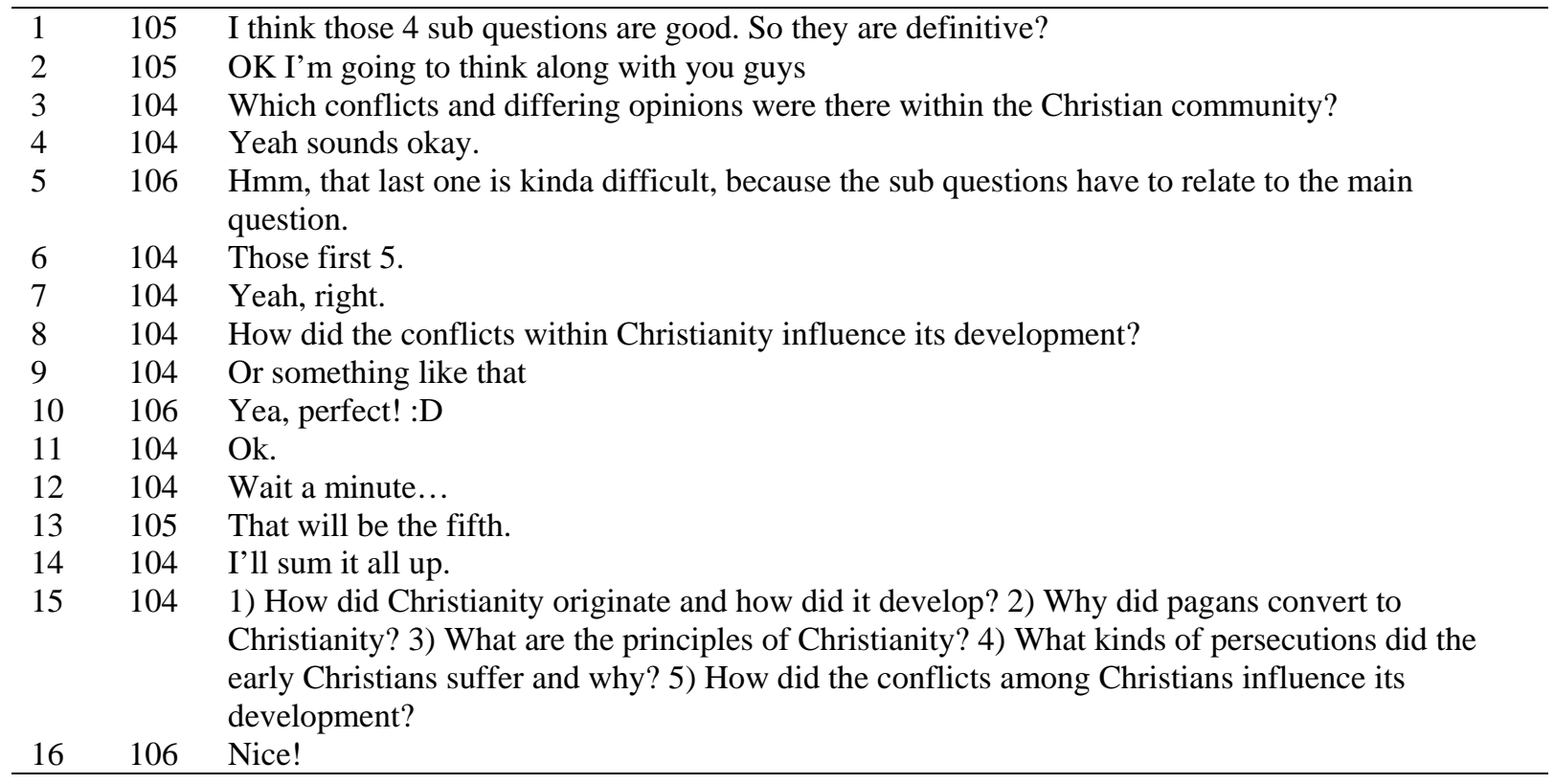

The two fragments illustrate these differences between low and high familiarity groups. The first fragment below shows a low familiarity group discussing questions they are going to address in their essay. As can be seen, each time a student proposes a question (lines 3,8 , and 15), this is quickly accepted by the other students. In contrast, in fragment 2 the group members are constantly critical of each others' proposals (e.g, lines $6,8,10,13$, and 17). These fragments illustrate the abovementioned finding that in high familiarity groups, students adhered to more critical and exploratory group norms. In summary, there seems to be sufficient evidence to support $H 1$.

Fragment 2: High familiarity group (line number, student ID, chat message).

\begin{tabular}{lll}
\hline 1 & 113 & Ok, lets start \\
2 & 115 & W8 a minute \\
3 & 113 & :P \\
4 & 114 & :D \\
5 & 115 & We should first make those 5 categories, right? \\
6 & 113 & Shouldn't we decide on them while reading? \\
7 & 113 & Like, you could think of them then. \\
8 & 115 & Yeah, when you decide on a category based on 1 source, the rest may not fit within that category. \\
9 & 115 & If we just think of 5 categories, we can divide all sources over those five. \\
\hline
\end{tabular}




\begin{tabular}{lll}
\hline 10 & 113 & But right now we do not have a clue what they are all about? \\
11 & 115 & Christianity? \\
12 & 114 & Sharp... reeeeally sharp! \\
13 & 113 & No, I think we better discuss those categories after we read it all. \\
14 & 115 & But then you have to remember 13 sources. \\
15 & 115 & How we'll categorize them? \\
16 & 114 & OK, but how are we going to categorize it? \\
17 & 113 & Yeah, but can't you just think of 5 while reading? \\
18 & 114 & This sucks! \\
\hline
\end{tabular}

\section{Perception of online collaboration and communication}

The effect of familiarity on group members' perceptions of their online behavior is also reported in Table 4. Familiarity had a significant positive effect on both perceptions of positive group behavior and perceived effectiveness of group task strategies. Thus, students who are familiar with their fellow group members perceive their collaboration as more positive and rate their group task strategies as more effective. Furthermore, familiarity was found to have a significant negative effect on perceptions of negative group behavior. This indicates that in familiar groups, students report less negative group behavior. In sum, these findings support $H 2$.

\section{Collaborative activities}

When analyzing the effect of familiarity on students' collaborative activities, two predictors were added to the multilevel model. In addition to familiarity, the number of chat messages typed was also included in the model to account for the fact that some groups typed more messages than others. By including this predictor, the effect of the familiarity could be investigated independent of number of messages typed by students. Familiarity was found to be a significant predictor for several collaborative activities. On the one hand it had significant positive effects on (a) social support (SociSupp, $\beta=1.72, p=.05$ ), and (b) social resistance messages (SociResi, $\beta=1.61, p<.00$ ). In contrast, familiarity led to significantly less (a) task-related questions (TaskQues, $\beta=-0.78, p=.04$ ), (b) monitoring of task activities (MTaskMoni, $\beta=-1.99, p=.01$ ), (c) positive evaluations of task activities (MTaskEvl+, $\beta=-0.59$, $p=.03$ ), (d) greetings (SociGree, $\beta=-1.30, p=.00$ ), and (e) messages indicating loss of shared understanding (SociUnd-, $\beta=-0.75, p=.03$ ). These results are mostly in line with $H 3$.

\section{Group performance}

To examine the last hypothesis, each group received performance scores for the different parts of the group task. Since these scores were given for the entire group, familiarity ratings also needed to be aggregated to the group-level by summing the familiarity ratings that each student gave to his or her group members. These aggregated familiarity ratings were subsequently used as a predictor for group performance. Because in this case, both variables were at the same level, namely the group-level, ordinary regression analyses were used instead of multilevel analyses. The results of the regression analyses are given in Table 5 . As can be seen, no significant effects of familiarity on group performance were found. Thus there seems to be no evidence to support $H 4$.

Table 5: Regression analyses of the effect of familiarity on group performance.

\begin{tabular}{lccc}
\hline & $B$ & $S E B$ & $\beta$ \\
\hline $\begin{array}{l}\text { Part 1 } \\
\text { - Conceptual content and argumentation }\end{array}$ & -.01 & .02 & .10 \\
$\quad$ Presentation & -.02 & .01 & -.25 \\
Part 2 & & & \\
& -.04 & .03 & -.21 \\
Part 3 & & & \\
$-\quad$ Conceptual content and argumentation & -.02 & .04 & -.01 \\
$-\quad$ Presentation & -.02 & .03 & -.11 \\
\hline
\end{tabular}




\section{Conclusions and discussion}

This study investigated the effect of familiarity on CSCL. The results indicate that familiarity influences several aspects of online collaboration. Because familiar group members may be more comfortable expressing their disagreement with their teammates, it was expected that higher familiarity would be associated with more critical and exploratory group norm perceptions $(\mathrm{HI})$. This was confirmed. Furthermore, because it was expected that familiar groups would communicate and collaborate more fluidly and efficiently, more positive perceptions of the online communication and collaboration process were also anticipated. Indeed, our analyses confirmed that higher levels of familiarity were associated with more positive perceptions and less negative perceptions $(H 2)$. Also, familiarity was expected to influence students' collaborative activities (H3). Indeed, some expected effects were found. For example, higher familiarity was associated with fewer task-related questions, possibly due to the fact that communication is more efficient in those groups. Also, students who reported high levels of familiarity devoted less time to monitoring task-related activities. Again, this may be explained by the fact that coordination and communication and collaboration are more efficiently performed in familiar groups. This is also supported by the fact that students in familiar groups sent fewer messages indicating a loss of shared understanding, for example because there were fewer communication problems and ambiguities. On the other hand, familiar group members also exchanged more messages containing a negative accent. This may again be caused by the fact that group members are more comfortable communicating with each other, and are thus also more likely to voice negative opinions (Gruenfeld et al., 1996). This finding mirrors the finding by Smolensky et al. (1990) that familiarity tended to increase negative speech. It is, however, interesting to note that in familiar groups positive messages were also sent more often. The last hypothesis $(H 4)$ addressed the influence of familiarity on group performance. However, no effect on performance was found. This is surprising, because familiar students reported more critical group norm perceptions, perceived the collaboration more positively, and needed to devote less effort to coordination and asking questions. This may be explained in several ways. First, familiar students also engaged in negative interactions more often, which may have had a counterproductive effect. These negative interactions can undermine group climate and group collaboration, ultimately resulting in a decreased group performance. Previous research seems to confirm this assumption, as Wilson, Straus, and McEvily (2006) found that negative interactions decreased trust among group members, while Smolensky et al. (1990) found a negative relationship between negative interactions and group performance.

Several limitations of this study should be kept in mind. First, this study was set up as a quasi-experiment. Students were not assigned to either low or high familiarity conditions based on students' ratings of all of their classmates. Rather, they were first randomly assigned to groups before their familiarity with each other was established. This resulted in a somewhat skewed division of low versus high familiarity groups (8 groups of three strangers, 19 groups with one familiar relationship and two stranger relationships, 3 groups with two familiar relationships and one stranger relationship, and 5 groups consisting of three students who were all familiar with each other). This skewed division may have had an impact on our results. Second, students in this study were 15 to 18 years old. At this age, students may be sensitive to social and peer factors (c.f., Leaper \& Smith, 2004), which may influence the impact of familiarity. Older or younger students may behave differently in familiar or unfamiliar settings. Third, an effect of familiarity on critical and exploratory group norms perceptions was found. This study did not investigate in depth whether students' online discussions also reflected these group norms. In other words, students perceived their discussions to be more critical and exploratory, but we do not for sure know if this actually was the case. If there is a difference between students' perceptions and actual behavior (e.g., students report they are more critical, when in fact they are not), this may be an additional explanation for why no influence of familiarity was found on group performance. On the other hand, we were able to provide collaboration fragments that illustrated the expected differences between low and high familiarity groups. This may also help to explain why familiar groups did not outperform unfamiliar groups. In sum, the mentioned limitations emphasize the need for additional research into the possibly differential effects of familiarity.

The goal of educational innovation is to make learning more efficient so that learners learn the same amount of material in a shorter time span, and/or make learning more effective so that learners learn more in the same time span, and/or make learning more enjoyable such that the affective learning experience is pleasing and learners will want to learn (Kirschner, 2004). Educational research in general and CSCL-research in particular tend to focus on determining how specific tools, environments, or student characteristics affect either the effectivity and/or efficiency of online collaboration. In the research reported here, although familiarity was not found to have an effect on group performance, it still had very important positive consequences for the way students collaborated in a CSCL environment. Familiarity clearly led to a more enjoyable collaborative experience among group 
members. When composing online groups, familiarity of group members should therefore definitively be taken into account.

\section{References}

Adams, S. J., Roch, S. G., \& Ayman, R. (2005). Communication medium and member familiarity: The effects on decision time, accuracy, and satisfaction. Small Group Research, 36, 321-353.

Cicchetti, D. V., Lee, C., Fontana, A. F., \& Dowds, B. N. (1978). A computer program for assessing specific category rater agreement for qualitative data. Educational and Psychological Measurement, 38, 805-813.

Gruenfeld, D. H., Mannix, E. A., Williams, K. Y., \& Neale, M. A. (1996). Group composition and decision making: How member familiarity and information distribution affect process and performance. Organizational Behavior and Human Decision Processes, 67, 1-15.

Hollingshead, A. B., \& McGrath, J. E. (1995). Computer-assisted groups: A critical review of the empirical research. In R. A. Guzzo, E. Salas \& Associates (Eds.), Team effectiveness and decision making in organizations (pp. 46-78). San Francisco: Jossey-Bass.

Janssen, J., Erkens, G., \& Kanselaar, G. (2007). Visualization of agreement and discussion processes during computer-supported collaborative learning. Computers in Human Behavior, 23, 1105-1125.

Kenny, D. A., Kashy, D. A., \& Cook, W. L. (2006). Dyadic data analysis. New York/London: The Guilford Press.

Kiesler, S., \& Sproull, L. (1992). Group decision making and communication technology. Organizational Behavior and Human Decision Processes, 52, 96-123.

Kirschner, P. A. (2004). Design, development, and implementation of electronic learning environments for collaborative learning. Educational Technology Research and Development, 52(3), 39-46.

Kirschner, P. A., Martens, R. L., \& Strijbos, J. W. (2004). CSCL in higher education? A framework for designing multiple collaborative environments. In J. W. Strijbos, P. A. Kirschner \& R. L. Martens (Eds.), What we know about CSCL, and implementing it in higher education (pp. 3-30). Boston: Kluwer Academic Publishers.

Leaper, C., \& Smith, T. E. (2004). A meta-analytic review of gender variations in children's language use: Talkativeness, affiliative speech, and assertive speech. Developmental Psychology, 40, 993-1027.

Mennecke, B. E., Hoffer, J. A., \& Valacich, J. S. (1995, January). An experimental examination of group history and group support system use on information sharing performance and user perceptions. Paper presented at the 28th Annual Hawaii International Conference on Systems Science (HICSS), Kohala Coast, HI.

Mukahi, T., \& Corbitt, G. (2004, January). The influence of familiarity among group members and extraversion on verbal interaction in proximate GSS sessions. Paper presented at the 37th Annual Hawaii International Conference on System Sciences (HICSS'04), Kohala Coast, HI.

Orengo Castellá, V., Zornoza Abad, A. M., Prieto Alonso, F., \& Peiró Silla, J. M. (2000). The influence of familiarity among group members, group atmosphere and assertiveness on uninhibited behavior through three different communication media. Computers in Human Behavior, 16, 141-159.

Postmes, T., Spears, R., \& Cihangir, S. (2001). Quality of decision making and group norms. Journal of Personality and Social Psychology, 80, 918-930.

Smolensky, M. A., Carmody, M. A., \& Halcomb, C. G. (1990). The influence of task type, group structure and extraversion on uninhibited speech in computer-mediated communication. Computers in Human Behavior, 6, 261-272.

Tuckman, B. W. (1965). Developmental sequence in small groups. Psychological Bulletin, 63(364-399).

Van den Bossche, P., Gijselaers, W. H., Segers, M., \& Kirschner, P. A. (2006). Social and cognitive factors driving teamwork in collaborative learning environments: Team learning beliefs and behaviors. Small Group Research, 37, 490-521.

Wegerif, R., Mercer, N., \& Dawes, L. (1999). From social interaction to individual reasoning: An empirical investigation of a possible socio-cultural model of cognitive development. Learning and Instruction, 9 , 493-516.

Wilson, J. M., Straus, S. G., \& McEvily, B. (2006). All in due time: The development of trust in computer-mediated and face-to-face teams. Organizational Behavior and Human Decision Processes, 99, 16-33.

\section{Acknowledgements}

This study is part of the Computerized Representation of Coordination in Collaborative Learning (CRoCiCL) project. This project is funded by NWO, the Netherlands Organisation for Scientific Research under project number 411-02-121. 